\title{
Phytopathology
}

\section{Mixtures as a Fungicide Resistance Management Tactic}

\author{
Frank van den Bosch, Neil Paveley, Femke van den Berg, Peter Hobbelen, and Richard Oliver
}

First, third, and fourth authors: Rothamsted Research, West Common, Harpenden, AL5 2JQ, United Kingdom; second author: ADAS High Mowthorpe, Dugglesby YO17 8BP, United Kingdom; and fifth author: Environment \& Agriculture, Centre for Crop and Disease Management (CCDM), Curtin University, Bentley, WA 6102, Australia.

Accepted for publication 14 August 2014.

\begin{abstract}
van den Bosch, F., Paveley, N., van den Berg, F., Hobbelen, P., and Oliver, R. 2014. Mixtures as a fungicide resistance management tactic. Phytopathology 104:1264-1273.

We have reviewed the experimental and modeling evidence on the use of mixtures of fungicides of differing modes of action as a resistance management tactic. The evidence supports the following conclusions.

1. Adding a mixing partner to a fungicide that is at-risk of resistance (without lowering the dose of the at-risk fungicide) reduces the rate of selection for fungicide resistance. This holds for the use of mixing partner fungicides that have either multi-site or single-site modes of action. The resulting predicted increase in the effective life of the at-risk fungicide can be large enough to be of practical relevance. The more effective the mixing partner (due to inherent activity and/or dose), the larger the reduction in selection and the larger the increase in effective life of the at-risk fungicide.

2. Adding a mixing partner while lowering the dose of the at-risk fungicide reduces the selection for fungicide resistance, without compromising effective disease control. The very few studies existing suggest that the reduction in selection is more sensitive to lowering the dose of the at-risk fungicide than to increasing the dose of the mixing partner.

3. Although there are very few studies, the existing evidence suggests that mixing two at-risk fungicides is also a useful resistance management tactic.

The aspects that have received too little attention to draw generic conclusions about the effectiveness of fungicide mixtures as resistance management strategies are as follows: (i) the relative effect of the dose of the two mixing partners on selection for fungicide resistance, (ii) the effect of mixing on the effective life of a fungicide (the time from introduction of the fungicide mode of action to the time point where the fungicide can no longer maintain effective disease control), (iii) polygenically determined resistance, (iv) mixtures of two at-risk fungicides, (v) the emergence phase of resistance evolution and the effects of mixtures during this phase, and (vi) monocyclic diseases and nonfoliar diseases. The lack of studies on these aspects of mixture use of fungicides should be a warning against overinterpreting the findings in this review.
\end{abstract}

The production of many crop species is dependent on fungicides to control diseases. Evolved resistance is a significant threat to the efficacy of current fungicides and the optimization of tactics to extend their useful life is a priority. The effectiveness of mixtures of two or more different modes of action as a fungicide resistance management method is subject of an extensive discussion since the late 1970s. Some authors favor mixtures, while others have largely dismissed mixtures as a resistance

Corresponding author: F. van den Bosch;

E-mail address: frank.vandenbosch@Rothamsted.ac.uk

* The $e$-Xtra logo stands for "electronic extra" and indicates that the online version contains five supplemental appendices.

http://dx.doi.org/10.1094/PHYTO-04-14-0121-RVW

(C) 2014 The American Phytopathological Society management tactic $(2,53)$. The development of sound resistance management tactics requires exploration of the validity of these contrasting views. In this review we ask whether it is possible to draw generic conclusions or whether different situations require different tactics?

Resistance management methods are urgently discussed when new resistances are discovered and when a new mode of action is introduced. Unfortunately, in discussions on resistance management, it is often not explicit what the evidence is. In this review we present an overview of the existing evidence on mixtures as a method to prevent or delay the development of fungicide resistance. We will also identify the evidence that is missing currently.

There are four main reasons for considering the use of mixtures in a fungicide application program (5).

1. Broadening the spectrum. Pathogens are differentially sensitive to different active substances. If a spray program 
aims to control two or more pathogens it can, from a disease control viewpoint, be useful to spray mixtures of fungicides.

2. Improved disease control. Adding a mixing partner may improve the control of a pathogen.

3. As an insurance against resistance. Mixtures may be used as insurance against failure of one of the mixture components. If the pathogen to be controlled develops resistance to one of the mixture components, the other fungicide (of a different mode of action) can ensure that effective control is maintained.

4. Resistance management. Mixtures are frequently advocated as a resistance management tactic, i.e., specifically to extend the effective life of a fungicide by slowing the rate of evolution of resistance in the pathogen population.

In this review we exclusively discuss the use of mixtures for resistance management. Hence, what we present here is only one aspect of what needs to be considered when the use of mixtures is discussed.

In a recent review (63) we have shown that there is a simple governing principle that we have found to be a good predictor of whether particular resistance management tactics are likely to be effective. The determinant of effectiveness is whether a tactic reduces the selection coefficient and exposure time

$$
s T=\left(r_{S}-r_{R}\right) T
$$

where $s=r_{S}-r_{R}$ is the selection coefficient, $r_{S}$ and $r_{R}$ are the intrinsic rate of increase of the sensitive and the resistant strain, respectively (40), and $T$ is the time the pathogen is exposed to the fungicide. The intrinsic rate of increase is the net increase in pathogen density per cycle of infection per pathogen lesion. We will loosely describe this parameter as the epidemic growth rate. In population genetics, the fitness of a pathogen strain is defined as the intrinsic rate of increase, $r$, of that pathogen strain (13). The selection coefficient provides a measure of the increase in the resistant strain, as a fraction of the total pathogen population, per cycle of infection, and is related (nonlinearly) to the period of time that a new mode of action will remain effective. Here, we use the governing principle of selection coefficient and exposure time to explore resistance management using mixtures, and compare the results with published experimental evidence.

\section{INSIGHTS FROM THE GOVERNING PRINCIPLE}

The effectiveness of mixtures as a resistance management tactic is affected by the doses of the mixture components. Calculation of the selection coefficient, $s$, in a mixture of an at-risk fungicide and a mixing partner gives some initial insight into the effect of dosages on the rate of selection for fungicide resistance. If the density of the resistant strain is low, the sensitive strain is the key determinant of disease control. The growth rate of the sensitive strain, $r_{S}$, then is a measure of the increase in disease severity. We use this growth rate as a measure of the level of disease control achieved by the fungicide applications. We assume, as the simplest case, that the resistant strain is completely resistant to the at-risk fungicide, suffers no fitness cost (in the absence of any fungicide), and that the mixing partner has the same effect on the fitness of both strains. Thus,

$$
\begin{gathered}
r_{S}=r \theta\left(D_{M}\right) \alpha\left(D_{A}\right) \\
r_{R}=r \theta\left(D_{M}\right)
\end{gathered}
$$

where $r$ is the fitness of the strains in the absence of the fungicides, $D_{A}$ is the dose of the at-risk fungicide, $D_{M}$ is the dose of the mixing partner, $\theta\left(D_{M}\right)$ is the fractional reduction of the fitness of the sensitive strain when using dose $D_{M}$ of the to-beprotected fungicide, and $\alpha\left(D_{A}\right)$ is the fractional reduction of the fitness of both the sensitive and the resistant strain when using dose $D_{A}$ of the mixing partner. Note that we modeled the effect of the fungicides as multiplicative, to represent each fungicide acting independently on the intrinsic rate of increased. As dose response curves we use exponentially decreasing fitness with dose with a lower asymptote, as this curve fits currently published dose response curves from field experiments. We thus have

$$
\begin{aligned}
& \theta\left(D_{M}\right)=1-\theta_{\max }\left(1-e^{-k_{M} D_{M}}\right) \\
& \alpha\left(D_{A}\right)=1-\alpha_{\max }\left(1-e^{-k_{A} D_{A}}\right)
\end{aligned}
$$

Substituting these gives the dependence of the selection coefficient on the dose of the at-risk fungicide and the mixing partner

$$
s\left(D_{A}, D_{M}\right)=r\left\{1-\theta_{\max }\left(1-e^{-k_{M} D_{M}}\right)\right\}\left\{\alpha_{\max }\left(1-e^{-k_{A} D_{A}}\right)\right\}
$$

and as rate of epidemic increase

$$
r_{S}=r\left\{1-\theta_{\max }\left(1-e^{-k_{M} D_{M}}\right)\right\}\left\{1-\alpha_{\max }\left(1-e^{-k_{A} D_{A}}\right)\right\}
$$

Figure 1 shows the effect of the dose of the at-risk fungicide and the dose of the mixing partner on the selection coefficient and on the growth rate of the epidemic. The lines in the graph are contour lines for values of the selection coefficient, $s$, and the epidemic growth rate, $r_{S}$. Both are expressed as fractions of the fitness of the pathogen population in the absence of the fungicides, $r$.

The figure shows that increasing the dose of the mixing partner (arrow 1) decreases the selection for fungicide resistance and increases the control of the pathogen (i.e., decreases the rate of epidemic growth). It is also possible to decrease the selection for fungicide resistance by decreasing the dose of the at-risk fungicide (arrow 3), though this would decrease the level of pathogen control. The effect of dose on selection has been determined (63, 64). The figure also shows that it is possible to increase the dose of the mixing partner, decrease the dose of the at-risk fungicide (arrow 2) and maintain disease control while decreasing the selection for fungicide resistance. In the next sections we focus on arrow 1 and arrow 2 in more detail and compare predictions against published evidence for polycyclic diseases (we consider monocyclic diseases in Box 1).

\section{THE EXPERIMENTAL EVIDENCE}

Adding a mixing component to an at-risk fungicide (arrow 1). Whether adding a mixing partner to an at-risk fungicide to which resistance is developing without reducing the dose of the at-risk fungicide is a valid resistance management tactic has been the subject of intensive discussions since the 1970s. The discussion initially involved modeling studies. Several researchers have suggested that "mixing only reduces the build-up of pesticide resistance by reducing the required dose of the pesticides that are mixed" (2). Others suggested that arrow 1 is a valid resistance management method. Over the last few decades sufficient experimental studies have been published to allow a test of these contradictory views. Relevant studies have been reported $(3,4,8,9,11$, $15,16,18,20-22,24,30,31,35,37-39,41-43,46-49,57-59)$. In our analysis we separate studies with mixing partners that are multisite acting from mixing partners that are single-site acting fungicides. In the former case, the risk of resistance in the mixing partner can be largely discounted, whereas single-site fungicide 
mixing partners are also at-risk. The results are given in Online Appendix 2, but a summary is provided below. (Note: the dose of the fungicide against which the development of resistance is measured is not changed in these treatments.)

- Mixing partner is a multi-site fungicide. We found 17 publications with a total of 27 pathogen-crop-fungicide mixtures tested for their effect on fungicide resistance selection compared with the use of the at-risk solo fungicides. Of these 27 combinations, 24 showed reduced selection for fungicide resistance in the at-risk fungicide when used in mixture.

- Mixing partner is a single-site fungicide. We found 17 publications with a total 24 pathogen-crop-fungicide mixtures tested for their effect on the selection of resistance. In 20 cases the mixture delayed the build-up of resistance compared with the use of the at-risk fungicide as a solo product.

The extensive experimental evidence thus shows that adding a mixing component to an at-risk fungicide, not changing the dose of the at-risk fungicide, does reduce the selection for fungicide resistance. There is no difference between mixing with a multisite mixing partner and mixing with a single-site mixing partner to which no resistance is developing. With a total of 50 experiments of which $86 \%$ show a reduced selection for fungicide resistance in a mixture even though the dose of the at-risk fungicide is not reduced, we conclude that the evidence suggests that this is a valid resistance management method in many cases. Only

FOOTNOTE: In fact, fungicides do not directly affect the intrinsic rate of increase, $r$, of the pathogen strains, but rather affect the life-cycle parameters of the pathogen such as infection efficiency, latent period, spore production rate, and infectious period. These life-cycle parameters form the fundamental building blocks of the intrinsic rate of increase. In Online Appendix 1 we show that qualitatively the same results emerge when we model the effect of the fungicides on lifecycle parameters and use these to calculate the consequences for the intrinsic rate of increase. one experiment found an increased selection in the mixture. We refer to Box 2 for a discussion of this case. We also refer to Box 1 for a discussion on monocyclic pathogens.

Adding a mixing component and lowering the dose of the at-risk fungicide (arrow 2). Lowering the dose of the at-risk fungicide in a mixture may compromise effective control. However, our study of the selection coefficient (Fig. 1) predicts that it should be possible to combine mixing and dose reduction in such a way that effective control is not compromised. We have found 13 papers that discuss this scenario, summarized in Online Appendix $3(7,17,18,29,31,35,44,46,48,49,55,59,66)$. The comparison is between the selection for fungicide resistance imposed by the use of the at-risk fungicide as solo product at the initial dose and the mixture with the reduced dose of the at-risk fungicide.

- Mixing partner is a multi-site fungicide. A total of eight publications with 11 pathogen-crop-fungicide cases have been studied. In eight cases it was found that the mixture delays the selection for fungicide resistance in the at-risk fungicide compared with using the at-risk fungicide as pure product. In six of the eight publications the disease severity was measured during the experiments and in all cases effective control was similar in the solo use and the mixture treatment.

- Mixing partner is a single-site fungicide. We found six publications with a total of nine pathogen-crop-fungicide mixtures tested. In seven cases the selection for fungicide resistance of the at-risk fungicide was reduced by the mixture. In all studies the authors confirm that disease control was at a similar level as in the solo product treatment.

The experimental evidence substantiates the predictions from the selection coefficient (Fig. 1). Both adding a mixture partner and reducing the dose of the at-risk fungicide will reduce selection (Box 2 provides discussion on the exceptions). It is possible to decrease the dose of the at-risk fungicide, maintain the level of control, and decrease the selection for fungicide resistance (arrow 2 in Fig. 1). We stress here however that for each mixture that may enter the market, field experiments are needed to prove that effective control will not be compromised.
FIGURE 1

The selection coefficient, $s$, expressed as a fraction of the intrinsic rate of increase, $r$, as dependent on the dose of the at-risk fungicide and the dose of the mixing partner. The rate of epidemic increase, $r_{S}$, expressed as a fraction of the intrinsic rate of increase, $r$, as dependent on the dose of the to-beprotected fungicide and the dose of the mixing partner. Parameter values used are as follows: $k_{M}=$

$k_{A}=2, \alpha_{\max }=0.95, \theta_{\max }=0.75$. The three arrows represent options for changing the doses of the two fungicides (text provides further explanation).

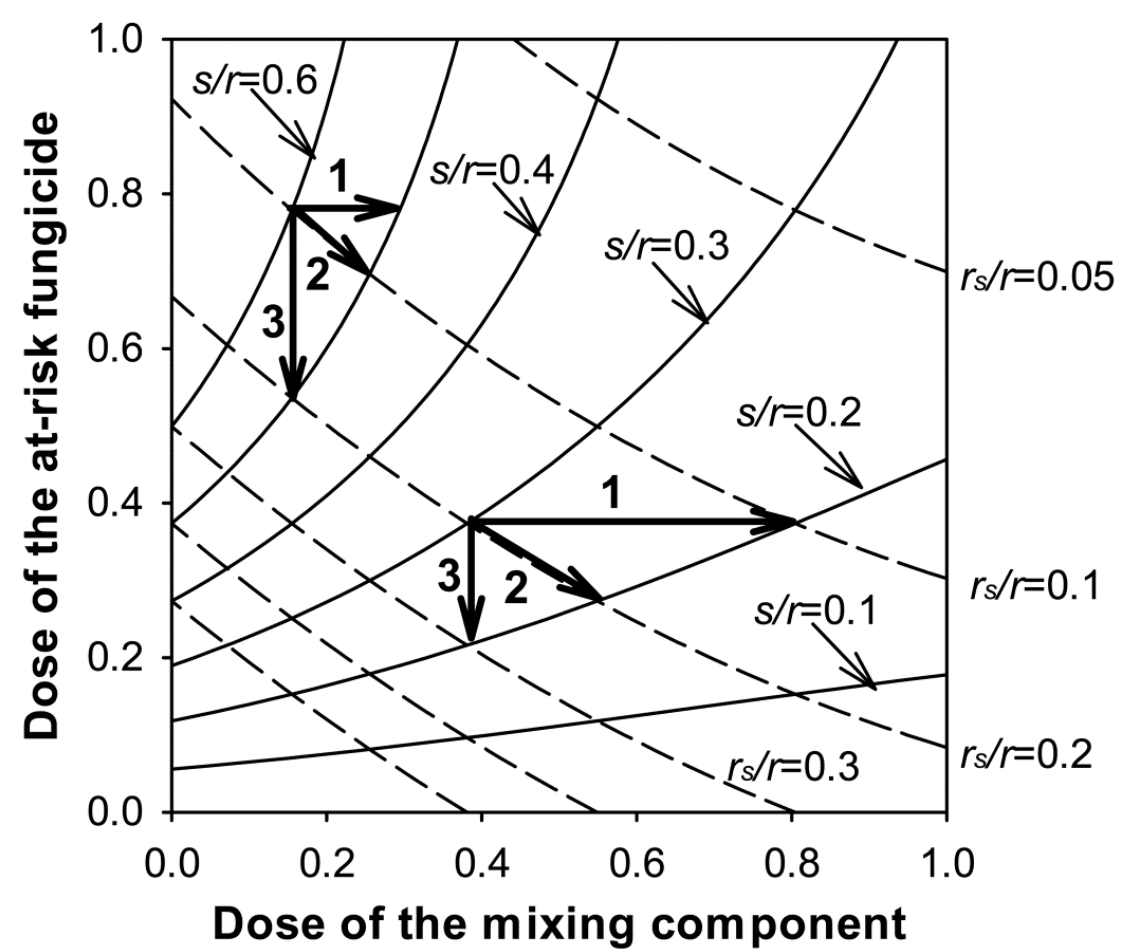


Further evidence on dose of the mixing components. We have shown that adding a mixing partner to an at-risk fungicide to which resistance is developing will reduce the rate of selection for fungicide resistance. Does this imply that the larger the dose of the mixing partner, the larger the reduction in selection for resistance? This question is of importance in making decisions on dose of the mixing components when developing mixtures. There are only four papers (Online Appendix $4[3,16,21,37]$ ) that estimate the frequency of resistance for sprays with mixtures with different dosages of the mixing partner. These papers study, in total, nine pathogen-fungicide-mixing partner combinations. Although the amount of evidence is small all experiments suggest that increasing the dose of the mixing partner decreases the selection for fungicide resistance. Very likely this further decrease with increasing dose will be limited by the dose response curve approaching its limiting value, but clearly all experiments were done with dosages below such values. In the next section we will return to this topic when describing model studies.

What has a larger effect on selection for fungicide resistance, increasing the dose of the mixing partner or decreasing the dose of the at-risk fungicide? Obviously when we decrease the dose of the at-risk fungicide disease control efficacy decreases, and when increasing the dose of the mixing component disease control efficacy (and cost) increases. We thus have to make sure that changing the doses in the mixture does not compromise effective control. Figure 1 clearly shows that the answer depends on the dosage of both fungicides. Further exploration of equation 6 shows that the shape of the dose response curve also affect whether reducing the dose of the at-risk fungicide or increasing the dose of the mixing partner has the larger effect on reducing

\section{BOX 1}

Monocyclic versus polycyclic pathogens. In this box we consider a possible difference between mono- and polycyclic pathogens in the effect on selection for fungicide resistance of adding a mixing partner to an at-risk fungicide. The selection coefficient, defined as the difference in the exponential growth rates of the resistant and the sensitive strain, is derived from a model where pathogen generations overlap due to the continuous reproduction and continuous death of lesions. Thus, the simple model mimics a polycyclic pathogen. In this case adding a mixing partner to an at-risk fungicide is expected to reduce the rate of selection for fungicide resistance. More detailed models for polycyclic pathogens, such as discussed in Online Appendix 1 and in the model by Hobbelen et al. (27), suggest the same conclusion. Does this conclusion also hold for monocyclic pathogens?

If we denote by $P_{S, n}$ and $P_{R, n}$ the density of the sensitive and the resistant strain in generation $n$, the equivalent of the exponential growth model, equations 1.1 and 1.2, for a discrete time model are

$$
\begin{gathered}
P_{S, n+1}=R_{0 S} P_{S, n} \\
P_{R, n+1}=R_{0, R} P_{R, n}
\end{gathered}
$$

where $R_{0 S}$ and $R_{0 R}$ are the net-reproductive number of the sensitive and the resistant strain, respectively. The net-reproductive number is the number of daughter lesions per mother lesion when availability of susceptible host is not limiting (62 provides an introduction to this topic). The frequency of resistance in generation $n+1, \rho_{n}$, is calculated from

$$
\rho_{n+1}=\frac{R_{0 R} P_{R n}}{R_{0 S} P_{S n}+R_{0 R} P_{R n}}
$$

The at-risk fungicide affects the net-reproduction number of the sensitive strain and the mixing partner affects the net-reproductive number of both pathogen strains. We can then write

$$
\begin{gathered}
R_{0 s}=R_{0} \theta\left(D_{M}\right) \alpha\left(D_{A}\right) \\
R_{0 R}=R_{0} \theta\left(D_{M}\right)
\end{gathered}
$$

where $R_{0}$ is the net-reproductive number of both strains in the absence of fungicide use, $\theta\left(D_{A}\right)$ is the fractional reduction of the netreproduction of the sensitive strain when using dose $D_{A}$ of the to-be-protected fungicide, and $\alpha\left(D_{M}\right)$ is the fractional reduction of the netreproduction of both the sensitive and the resistant strain when using dose $D_{M}$ of the mixing partner. Substituting equations 1.4 and 1.5 into equation 1.3 , we find

$$
\rho_{n+1}=\frac{R_{0} \theta\left(D_{M}\right) P_{R n}}{R_{0} \theta\left(D_{M}\right) \alpha\left(D_{A}\right) P_{S n}+R_{0} \theta\left(D_{M}\right) P_{R n}}=\frac{R_{0} P_{R n}}{R_{0} \alpha\left(D_{A}\right) P_{S n}+R_{0} P_{R n}}
$$

From which we see that the effect of the mixing partner cancels out, implying the that mixing partner has no effect on selection for resistance and we conclude that, in our simple model for a monocyclic pathogen, adding a mixing partner to an at-risk fungicide does not reduce the selection for resistance.

The reason for the difference between the polycyclic and the monocyclic pathogens is that in the polycyclic case several pathogen generations live at the same moment and each generation has been under a different selection history, with "older" generations having experienced less selection than "younger" generations. This can be seen by calculating, using equations 1.1 and 1.2, two sequential generations. Then, assuming that a fraction $\mu$ of the first generation survives and lives at the same time as the second generation it is easily seen that the effect of the mixing partner no longer cancels out from the calculation of the frequency of resistance.

The reasoning above suggests that adding a mixing partner to an at-risk fungicide may not reduce selection for monocyclic species. Interestingly, the only experiment on mixing using Pseudocercosporella herpotrichoides causing eyespot disease in wheat (24) suggests that adding a mixing partner does reduce selection.

We conclude that there is an urgent need to develop models and conduct resistance experiments on monocyclic pathogens, because the effect of fungicide mixtures on selection for resistance may or may not be different from the effect of mixing in polycyclic species. 
the selection rate (data not shown). Hence, optimizing doses of mixtures remains a matter of case-by-case study.

There are four papers describing field experiments with treatments reducing the dose of the at-risk fungicide as well as increasing the dose of the mixing partner (Online Appendix 5 $[30,31,37,42])$. These papers describe six pathogen-fungicidemixing partner combinations. Generally these experiments involve the full dose of the at-risk, with a full dose of the mixing partner or a full dose of the at-risk plus a half or a full dose of the mixing partner.

All six pathogen-fungicide-mixing partner combinations show that reducing the dose of the at-risk fungicide reduces the selection for resistance more than increasing the dose of the mixing partner. All these experiments relate to field relevant treatment programs. The evidence base is quite small, so we cannot conclude that reducing the dose of the at-risk fungicide is the more effective resistance management tactic. More work in this area is needed and it may very well turn out to be a question that needs to be studied on a case-by-case basis.

\section{FROM QUALITATIVE TO QUANTITATIVE ANALYSIS}

Is the reduction in selection large enough to matter? The discussion so far has described consistent qualitative trends relating to mixing per se, mixing multi-site or single-site fungicides, and the relative doses of the two fungicides. We now address whether the reduction in selection for fungicide resistance from the use of mixtures is large enough to be of practical relevance.

The reduction in selection for resistance certainly depends on the crop-pathogen-fungicide combination and so the practical

\section{BOX 2}

A closer look at the exceptions. In this box we discuss the two cases that contradict the predictions from the governing principle coefficient. Köller and Wilcox (35) studied the effect of mixtures on the selection for fenarimol resistance in Venturia inaequalis (causal organism of apple scab). Resistance to fenarimol is polygenically determined in Nectria haematococca var. cucurbitae with at least nine loci involved (33) and there are phenotypes known that show a reduced uptake of fenarimol in Aspergillus nidulans (14). There are strains with low and with high levels of resistance. Secondly, McGee and Zuck (44) studied the effect of mixtures on the selection for benomyl resistance in the same pathogen species. High levels of resistance are conferred by a single gene mutation (34) but there are also low resistance strains known $(34,56)$. The genetics of the low resistance strains is not known but might be related to efflux pump mechanisms.

We have shown previously (64) that low resistance levels/ partial resistance may be associated with dose response curves of the resistant and the sensitive pathogen strains that converge at higher dose. If this is the case it is possible that the selection for fungicide resistance is lower at high dose than at low fungicide dose. The two cases may be examples of this mechanism. There are however no data available for any fungicide-pathogen combination that allow us to see if dose response curves converge within the range of doses permitted. We have discussed (64) that research in this area is urgently needed because it may, in some cases, have consequences for resistance management. We reiterate here the need for experimental and modeling work on the existence of converging dose response curves for cases where the pathogen has partially resistant strains. relevance will require case-by-case studies. How can we quantify the delay in the build-up of resistance? Measurements of selection, the selection coefficient, or a related quantity, from field experiments or model studies gives some insight, but it does not tell us how much more durable the effective disease control from an at-risk fungicide will be due to using it in a mixture. To be relevant, mixtures must increase effective disease control by at least one growing season. We therefore need to measure the success of a resistance management method in terms of years of effective disease control after the fungicide is introduced (2527,60,61). The models calculating the number of years of effective disease control $(25-27,60)$ were parameterized for Mycosphaerella graminicola on winter wheat, and the fungicides pyraclostrobin as the at-risk fungicide and chlorothalonil as the mixing partner. Here we have done additional calculations with two different dose response curves for the mixing component (Fig. 2), one for chlorothalonil and one representing a hypothetical mixing partner with a lower disease control efficacy. The findings are summarized in Tables 1 and 2 .

Adding a mixing component to an at-risk fungicide, arrow 1. As found in the experimental evidence discussed earlier, the model calculations show that adding a mixing partner to an atrisk fungicide without lowering the dose of the at-risk fungicide reduces selection for resistance (Table 1). Moreover, the results show that the larger the dose of the mixing partner the further the selection coefficient is reduced, as was also found in the few papers presenting experimental evidence on this. Comparing the reduction of selection for resistance between mixing with chlorothalonil and mixing with a lower efficacy fungicide clearly shows that a mixing partner with lower efficacy is less effective in lowering the rate of selection for fungicide resistance.

The calculations of the effective life of the mixtures show that a reduced rate of selection goes paired with an increased effective life; using a mixing partner can increase the effective life of an atrisk fungicide by several years.

Two key conclusions thus are that to reduce the rate of selection for fungicide resistance and thereby increase the effective life of a fungicide we need to (i) use the highest possible dose of the mixing partner, and (ii) use the mixing partner that has the highest disease control efficacy. However, see the next section where two at-risk fungicides are mixed in the scenario where resistance is developing against both. Hence, using a mixing partner that is subject to significant resistance and correspondingly poor efficacy is not a useful resistance management tactic. This in turns means that the development of resistance to each active ingredient must be monitored on an ongoing basis.

Adding a mixing partner and lowering the dose of the atrisk fungicide, arrow 2 . The last columns of Tables 1 and 2 show that introducing a mixing partner and reducing the dose of the atrisk fungicide can further increase the effective life of the at-risk fungicide while maintaining effective control. Therefore, we can conclude that at least for the crop-pathogen-fungicide cases considered it may be possible to reduce the dose of the at-risk fungicide and therewith maximize the effectiveness of mixing as a resistance management tactic.

We note here, however, that there is only one modeling study on the practical consequences of using mixtures as a resistance management tactic. There is clearly a need for more studies to investigate the effect of mixtures on the effective life of fungicides.

\section{MIXING TWO AT-RISK FUNGICIDES}

An important question not answered so far is whether mixing two at-risk fungicides, against each of which resistance is developing or can develop, is a useful resistance management tactic. This is a highly relevant question as there are only a handful of multi-site, low-risk fungicides and these are generally of lower 
efficacy than single-site acting fungicides. Hence, for example, the new SDHI fungicides are being introduced in mixtures with triazoles $(12,54)$. There are two opposing forces to consider here. We have shown that adding a mixing partner $\mathrm{B}$ to an at-risk fungicide A will slow down the selection for resistance to A. However, adding an at-risk mixing partner B creates selection pressure for resistance against $\mathrm{B}$. The question thus is whether the gain, in terms of slowing down selection, from adding an at-risk fungicide to the spray program outweighs the loss of putting an additional fungicide at risk of resistance.

We have found four papers on experimental work studying the development of resistance when the pathogen develops resistance to both mixing components and the selection is measured for both $(4,39,57,65)$. Of these, the experiment presented by Zhang et al. (65) did not include the control in which the fungicides were used as solo active substance and can therefore not answer our questions.

- Brent et al. (4) measured the concurrent selection for resistance to tridemorph and to ethirimol by barley powdery mildew (Blumeria graminis f. sp. hordei). Comparing the selection by solo tridemorph with ethirimol plus tridemorph showed that the mixture had a lower selection rate for tridemorph resistance.

- Lorenz et al. (39) compared mixtures and solo use of fenpropimorph and triadimenol for wheat powdery mildew (Blumeria graminis f. sp. tritici). They showed a lower rate of resistance selection for resistance to either component by the mixture than the solo applications.

- Thygesen et al. (57) showed that mixing reduces the selection for both pyroclostrobin and epoxiconazole resistance in M. graminicola of wheat.

Though the number of applicable studies is only three, they all show that mixing two at-risk fungicides slows down the selection for resistance in both fungicides. However, these experiments did not address the net effect of putting a second fungicide at risk, as discussed above.

The work developed by Hobbelen et al. (27) is the only modeling study to assess the effective life of a mixture of two at- risk fungicides compared with solo use of these fungicides (on different fields at the same time) and sequential use (where use of one fungicide is delayed until the end of the other fungicide's effective life). Shaw (52), who also studied the development of resistance to two at-risk fungicides, did not compare selection due to solo product use with mixture use but compared mixture versus alternation. There are different scenarios to be considered here: (i) the pathogen population consists of three strains: a wild-type sensitive, a type resistant to fungicide $\mathrm{A}$, and a type resistant to fungicide $\mathrm{B}$; and (ii) the pathogen population consists of four strains, a wild-type sensitive, a type resistant to A, a type resistant to $\mathrm{B}$, and a strain resistant to $\mathrm{A}$ and $\mathrm{B}$.

Hobbelen et al. (26) only considered the second scenario. They modeled two sets of fields interconnected by spore exchange between crop growing seasons (the model was parameterized for $M$. graminicola in wheat, but such spore exchange between seasons is characteristic for a much broader range of foliar pathogens). Each set of fields could receive a different spray program. Two fungicides of different modes of action were available to control the pathogen and the pathogen evolved resistance to both. Hobbelen et al. (26) then compared the effective life of the two fungicides when used as a mixture of the fungicides with the use of the solo fungicides each on half of the fields (concurrent use). We also calculated (not in the publication) the effective life for sequential use in which one of the products is withheld from use, the other product used as solo product until its effective life is ended and then introducing the other fungicide (sequential use). They allowed the dose to be chosen in each case separately such that the effective life of the fungicides was maximized.

Key conclusions from this modeling study were that mixing two at-risk fungicides always gave an equal or higher effective fungicide life compared with either concurrent or sequential use of the solo products. Thus, mixing two at-risk fungicides is a useful anti-resistance management method. The difference in the maximum effective life between the mixture and the concurrent use tactic decreased when the frequency of the double resistant strain at the start of a treatment tactic decreased. The difference in

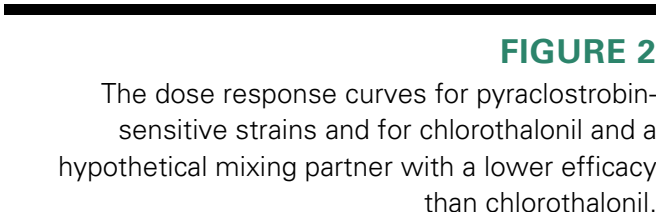

than chlorothalonil.

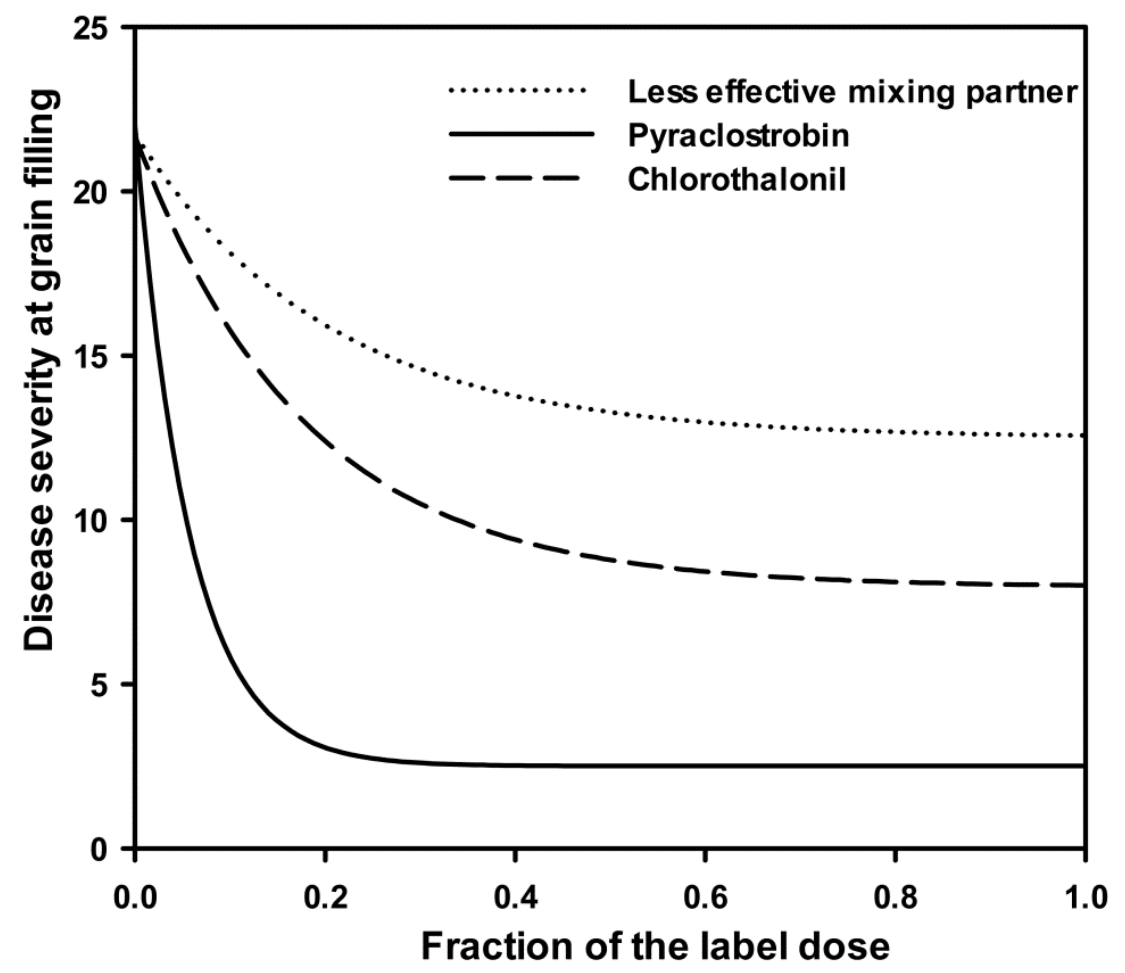


the maximum effective life between the mixture and the concurrent use tactic increased with increasing fitness costs of resistance and increasing sensitivity of the resistant strains to the high-risk fungicides. The maximum effective life of the mixture tactic was usually obtained by applying both high-risk fungicides at dose rates that provided just enough control of a severe epidemic and that resulted in an approximately equal selection pressure on both single resistant strains.

In summary, we can say that the available evidence suggests that mixing two at-risk fungicides is a useful resistance management tactic in the case where a strain resistant to both fungicides is present in the pathogen population, but that the number of studies on which this conclusion is based is too small to warrant generalization and the scale of the increased effective life is not always clear. The subject of mixtures of two at-risk fungicides is in need of further work. In Box 3 we also discuss a hypothetical situation in which two at-risk fungicides applied as mixture on a sexually reproducing pathogen may lead to the use of high dose strategies.

\section{RESISTANCE EMERGENCE}

So far we have discussed the situation where resistance is present in the pathogen population and is selected for by the use of fungicides; the selection phase (61). When a new fungicide mode-of-action is introduced, if no target-site resistant strains are present in the pathogen population, resistance has to emerge through mutants derived from the sensitive population. Once a resistant mutant has built up a subpopulation that is large enough not to die out due to demographic stochasticity, the resistant strain is said to have emerged (emergence phase, 61). The time between the introduction of the fungicide mode-of-action and the moment the subpopulation is large enough not to die out by chance is termed the emergence time (28).

The importance of the emergence phase is currently unknown. No data are available on pre-existence of resistance in the field. It is however of key relevance to develop an understanding of the relevance of the emergence phase and the effect of resistance management strategies on the length of the emergence phase. This is important because it is possible that a different set of resistance management strategies is effective in the emergence phase compared with the resistance management strategies that are effective in the selection phase.

Studying the emergence phase in field populations will be extremely difficult and may be impossible in practice. There is however a range of lab studies looking into the development of mutants under UV treatment. This type of treatment can possibly be adapted to study the emergence phase for a range of fungicide treatment methods. Also, microcosm studies in glasshouses may be feasible. Due to the difficulties of field experimentation modeling studies, mimicking field conditions will be a key tool.

Several authors have studied simple stochastic models for the emergence of escape mutants $(32,50,51)$ and have shown the effect of the pathogen's life-cycle parameters on the emergence of new pathogen strains. The models do not however lend themselves to quantification of the effect of fungicide spray programs on the emergence of fungicide resistance due to their abstract nature, not including key drivers such as seasonality in host

TABLE 1

The selection coefficient for resistance to the at-risk fungicide (azoxistrobin) in a range of mixtures with chlorothalonil and a hypothetical fungicide with a lower efficacy (Figure 2) ${ }^{\mathrm{a}}$

\begin{tabular}{|c|c|c|c|c|c|c|}
\hline \multirow[b]{2}{*}{$\begin{array}{l}\text { Dose of } \\
\text { mixing partner }\end{array}$} & \multicolumn{3}{|c|}{ Mixing partner is chlorothalonil } & \multicolumn{3}{|c|}{ Mixing partner with a lower efficacy } \\
\hline & $\begin{array}{c}\text { Dose of at-risk } \\
25 \%\end{array}$ & $\begin{array}{c}\text { Dose of at-risk } \\
50 \%\end{array}$ & $\begin{array}{c}\text { Dose of at-risk } \\
100 \%\end{array}$ & $\begin{array}{c}\text { Dose of at-risk } \\
25 \%\end{array}$ & $\begin{array}{c}\text { Dose of at-risk } \\
50 \%\end{array}$ & $\begin{array}{c}\text { Dose of at-risk } \\
100 \%\end{array}$ \\
\hline 20 & 0.50 & 0.61 & 0.72 & 0.55 & 0.71 & 0.82 \\
\hline 40 & 0.45 & 0.55 & 0.65 & 0.53 & 0.68 & 0.79 \\
\hline 100 & 0.41 & 0.49 & 0.59 & 0.51 & 0.64 & 0.75 \\
\hline
\end{tabular}

a The calculations were done with the model of van den Berg et al. (60) parameterized for Mycosphaerella graminicola on wheat. Exponential curves were fitted to the resistance frequency at harvest, and the parameter is the selection coefficient in units of per year.

TABLE 2

The effective life of mixtures of the at-risk fungicide (azoxistrobin) in a range of mixtures with chlorothalonil and a hypothetical fungicide with a lower efficacy (Figure 2)

\begin{tabular}{|c|c|c|c|c|c|c|}
\hline $\begin{array}{l}\text { Dose of } \\
\text { mixing partner }\end{array}$ & \multicolumn{3}{|c|}{ Mixing partner is chlorothalonil } & \multicolumn{3}{|c|}{ Mixing partner with a lower efficacy } \\
\hline 20 & 9 & 8 & 7 & 7 & 7 & 6 \\
\hline 40 & 11 & 9 & 8 & 8 & 7 & 6 \\
\hline 100 & 13 & 11 & 9 & 8 & 8 & 7 \\
\hline
\end{tabular}

a The calculations were done with the model of van den Berg et al. (60) parameterized for Mycosphaerella graminicola on wheat. The effective life is measured in units of years. 
density, and the fact the selection pressure (the fungicide) is not constant through time. We have shown that such drivers have strong effects on the outcome of selection processes $(25-27,61)$.

There is currently only one modeling study looking into the emergence phase of fungicide resistance (28). The model was derived from the models of Hobbelen et al. (25-27) as discussed above by representing the dynamics of the resistant strain by a stochastic event-driven model (6). The model was parameterized for M. graminicola on winter wheat (Triticum aestivum). Analysis

\section{BOX 3}

Mixtures of two at-risk fungicides and the dose rate debate. In this box we consider an exceptional case where a high dose of two at-risk fungicides may be required to reduce selection for resistance in a haploid sexual pathogen species. In our previous work we have shown that the vast majority of the evidence suggests that for plant pathogens high dosage leads to high rates of selection (64), but that there are several mechanisms not well investigated. This box adds another possible exception that is in need of further research.

Consider a haploid pathogen species and two at-risk fungicides, $A$ and $B$, to which high levels of resistance can develop through by a mutation in the genome. There is a gene with alleles making the pathogen sensitive, $A_{S}$, and resistant, $A_{R}$, to fungicide $A$. There is another gene with alleles making the pathogen sensitive, $B_{S}$, and resistant, $B_{R}$, to fungicide $B$. Now consider the use of a, say 50:50 mixture of fungicides $A$ and $B$. The dose of this mixture is plotted on the $x$-axis in Figure 3. On the $y$-axis is the infection efficiency of the pathogen with dose response lines for each of the possible genotypes. When the pathogen is sexually reproducing and the frequency of both the resistance alleles is small, most resistance alleles will be in pathogen individuals that are sensitive to the other fungicide. This is because any individual with genotype $A_{R} B_{R}$ that appears in the population will almost certainly mate an $A_{S} B_{S}$ individual because individuals with this genotype make up the vast majority of the pathogen population, and produce genotypes with one resistance allele combined with sensitivity to the other fungicide. Just as in the case of diploid sexual insects, as we discussed in van den Bosch et al. (64), higher dosages of the mixture may remove more resistance alleles from the pathogen population. Thus, delaying the development of individuals with a resistance allele for both fungicides.

We note here again that this is speculation and there is no existing evidence for this situation. The case of sexually reproducing pathogen species to which mixtures of two at-risk fungicides are used is in need of further work. Moreover, fungi are capable of asexual recombination and this may affect the dynamics of resistance genes as well. of mixture treatment strategies with the model showed that adding a not-at-risk fungicide to an at-risk fungicide may, as in the selection phase, also be effective in prolonging the emergence phase in the evolution of resistance to high-risk fungicides.

It is not possible to come to general conclusions about resistance management in the emergence phase of fungicide resistance evolution on the basis of one modeling study. Further work is needed in this area.

\section{DISCUSSION}

The experimental and theoretical evidence on the use of mixtures as a fungicide resistance management tactic leads to the following conclusions.

Conclusion 1. Adding a mixing partner to an at-risk fungicide (without lowering the dose of the at-risk fungicide) reduces the rate of selection for fungicide resistance. This holds for the use of multi-site as well as for the use of single-site fungicide as the mixing partner. A first model study suggests that the reduction of selection for resistance results in an increase of the effective life of an at-risk fungicide which is large enough to be of practical relevance. All existing evidence suggests that the larger the dose of the mixing partner the larger the reduction in selection and the larger the increase in effective life of the at-risk fungicide. A mixing partner fungicide with a lower efficacy will give a smaller reduction in selection rate.

Conclusion 2. Adding a mixing partner to an at-risk fungicide as well as lowering the dose of the at-risk fungicide also reduces the selection for fungicide resistance. The very few studies existing suggest that the reduction in selection is more sensitive to lowering the dose of the at-risk fungicide than to increasing the dose of the mixing partner. Several experimental as well as modeling studies show that it is possible to lower the dose of the at-risk fungicide without compromising effective disease control. However, effective disease control is a critical parameter that needs to be rigorously established when developing fungicide mixtures.

Conclusion 3. Although there is little evidence about the usefulness of mixing two at-risk fungicides as a resistance management tactic, the evidence suggests that mixing two at-risk fungicides, without intrinsic positive cross-resistance, is a useful resistance management tactic.

However. Most of the evidence available on mixtures to date relates to the selection for resistance of a fungicide to which a considerable resistance develops in one single (mutation) step, in mixture with a fungicide to which no resistance is developing, or at least the resistance development of the mixing partner is not considered. The review made clear that for this situation mixing is a useful resistance management tactic. This is, however, just a subset of the practically relevant cases of fungicide resistance development. We have discussed the mixture of two fungicides to both of which resistance is developing as a practically important and clearly different example that has received virtually no

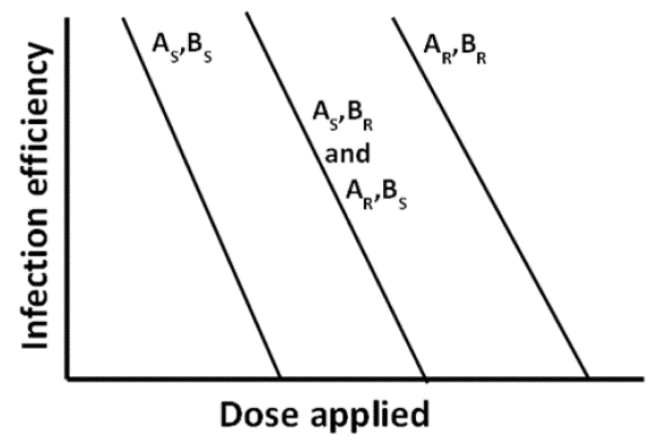

The infection efficiency of the four pathogen strains as a function of fungicide dose. The $A_{S}, B_{S}$ strain is sensitive to both fungicide $A$ and $B$, the $A_{S}, B_{R}$ strain is sensitive to fungicide $A$ and resistant to fungicide

$B$, the $A_{R}, B_{S}$ strain is resistant to fungicide $A$ and sensitive to fungicide $B$, and the $A_{R}, B_{R}$ strain is resistant to both fungicide $A$ and $B$. 
attention. Moreover, many pathogens develop resistance to fungicides through a sequence of small steps (sequence of mutations) each adding to (or occasionally detracting from (19)) the resistance. The evolution of azole resistance is a key example for which there is inadequate published evidence on mixture effects.

There are a number of examples in Botrytis cinerea in which resistance has been attributed to the overexpression of efflux pumps $(23,36,45)$. This is analogous to many causes of resistance to herbicides (10) and to clinical antibiotics (1). The current status of resistance in Botrytis has recently been reviewed. The impact of efflux pump mutations on the management of resistance to two or more fungicides that are susceptible to resistance by this mechanism has not been modeled and little or no data are available currently on which to test such a model. The contrasting impacts of efflux pump-mediated cross resistance coupled with potential fitness penalties needs further study. Hence, we caution that our conclusions should not be overinterpreted as they do not cover all possible relevant cases.

Conclusions 1 to 3 are generally well supported by evidence, but nevertheless are accompanied by some caveats. Results of experiments where no difference between treatments are measured have a smaller chance of being published than results of experiments where a difference is found. This may cause the effectiveness of mixing as resistance management method to be overestimated. Further, most of the experimental evidence relates to polycyclic pathogens and foliar-applied fungicides. In Box 2 we described a possible difference between monocyclic and polycyclic pathogens, but no evidence exists as yet. A final aspect is that all experimental evidence relates to cases where a single mutation (or other genetic change) confers a high level of resistance. Slow-shifting resistance is grossly absent from the mixtures literature. As also concluded in van den Bosch et al. (63), "Industry and regulatory decisions about fungicide resistance management often cannot wait for the accumulation of new evidence, so decisions should be taken by weighing the existing evidence and making judgments about the consequences should decisions prove to be wrong. With this review we hope to make a contribution towards such evidence-based resistance management."

\section{ACKNOWLEDGMENTS}

Rothamsted Research receives support from the Biotechnological and Biological Research Council (BBSRC) of the UK. This work was partly funded by the Chemicals Regulations Directorate (CRD) and Department for Environment Food and Rural Affairs (DEFRA) of the UK, and by the Australian Grains Research and Development (GRDC) of Australia.

\section{LITERATURE CITED}

1. Arias, C. A., and Murray, B. E. 2009. Antibiotic-resistant bugs in the 21st century-a clinical super-challenge. New Engl. J. Med. 360:439-443.

2. Birch, C. P. D., and Shaw, M. W. 1997. When can reduced doses and pesticide mixtures delay the build-up of pesticide resistance? A mathematical model. J. Appl. Ecol. 34:1032-1042.

3. Bolton, N. J. E., and Smith, J. M. 1988. Strategies to combat fungicide resistance in barley powdery mildew. Pages 367-372 in: British Crop Protection Conference, Pests and Diseases. British Crop Protection Council, Farnham.

4. Brent, K. J., Carter, G. A., Hollomon, D. W., Hunter, T., Locke, T., and Proven, M. 1989. Factors affecting build-up of fungicide resistance in powdery mildew in spring barley. Netherl. J. Plant Pathol. 95(S1):31-41.

5. Brent, K. J., and Hollomon, D. W. 2007. Fungicide resistance in crop pathogens: How can it be managed? Fungicide Resistance Action Committee. Global Crop Protection Federation, Brussels.

6. Cao, Y., Gillespie, D. T., and Petzold, L. R. 2006. Efficient step size selection for the tauleaping simulation method. J. Chem. Phys. 124:044109.

7. Carnegie, S. F., Cameron, A. M., and Haddon, P. 2008. Effects of fungicide and rate of application on the development of isolates of Polyscytalum pustulans resitant to thiabendazole and on the control of skin spot. Potato Res. 51:113-129.
8. Cohen, Y., and Samoucha, Y. 1989. Selection for matalaxyl reistance in potato crops infected with Pyhotophthora infestans: Effects of fungicides and initial frequency of resistant sporangia. Plant Pathol. 38:382-390.

9. Cohen, Y., and Samoucha, Y. 1990. Competition between oxadixylsensitive and -resistant field isolates of Phytophthora infestans on fungicide-treated potato crops. Crop Prot. 9:15-20.

10. Conte, S. S., and Lloyd, A. M. 2011. Exploring multiple drug and herbicide resistance in plants-Spotlight on transporter proteins. Plant Sci. 180:196-203.

11. Cooke, L. R., Locke, T., Lockley, K. D., Phillips, A. N., Sadiq, M. D. S., Coll, R., Black, L., Taggart, P. J., and Mercer, P. C. 2004. The effect of fungicide programmes based on epoxiconazole on the control and DMI sensitivity of Rhynchosporium secalis in winter barley. Crop Prot. 23:393406.

12. Cools, H. J., Hawink, N. L., and Fraaije, B. A. 2013. Constraints on the evolution of azole resistance in plant pathogenic fungi. Plant Pathol. 62:36-42.

13. Crow, J. F., and Kimura, M. 1970. An Introduction to Population Genetic Theory. Harper and Row, New York.

14. De Waard, M. A., and Nistelrooy, J. G. M. 1979. Mechanism of resistance to fenarimol in Aspergillus nidulans. Pest. Biochem. Physiol. 10:219-229.

15. Dovas, C., Skylakakis, G., and Georgopoulos, S. G. 1976. The adaptability of the benomyl-resistant population of Cercospora beticola in Northern Greece. Phytopathology 66:1452-1456.

16. English, A. R., and van Halsema, G. 1954. A note on the delay in the emergence of resistant xanthomonas and erwinia strains by the use of streptomycin plus terramycin combinations. Plant Dis. Rep. 38:429-431.

17. Forster, B., Chavaillaz, D., Steden, C., Radtke, W., Käsbohrer, M., and Kühl, A. 1994. Influence of split application of fenpropimorph mixtures on disease control and on the sensitivity of Erysiphe graminis f. sp. tritici. British Crop Protection Council Monographs No. 60:331-335.

18. Forster, B., and Staub, T. 1996. Basis for use strategies of anilinopyrimidineand phenylpyrrole fungicides against Botrytis cinerea. Crop Prot. 15:529-537.

19. Fraaije, B. A., Cools, H. J., Kim, S. H., Motteram, J., Clark, W. S., and Lucas, J. A. 2007. A novel substitution I381V in the sterol $14 \alpha$ demethylase (CYP51) of Mycosphaerella graminicola is differentially selected by azole fungicides. Mol. Plant Pathol. 8:245-254.

20. Genet, J.-L., and Jaworska, G. 2013. Characterization of European Plasmopara viticola isolates with reduced sensitivity to cymoxanil. Eur. J. Plant Pathol. 135:383-393.

21. Genet, J.-L., Jaworska, G., and Deparis, F. 2006. Effect of dose rate and mixtures of fungicides on selection for QoI resistance in populations of Plasmopara viticola. Pest Manag. Sci. 62:188-194.

22. Grabski, C., and Gisi, U. 1985. Mixtures of fungicides with synergistic interactions for protection against phenylamide resistance in Phytophthora. British Crop Protection Conference Monographs No. 31:315-318.

23. Hahn, M. 2014. The rising threat of fungicide resistance in plant pathogenic fungi: Botrytis as a case study. J. Chem. Biol. (In press.)

24. Hoare, F. A., Hunter, T., and Jordan, V. W. L. 1986. Influence of spray programmes on development of fungicide resistance in the eyespot pathogen of wheat, Pseudocercosporella herpotrichoides. Plant Pathol. 35:506-511.

25. Hobbelen, P. H. F., Fraaije, B., Lucas, J. A., Paveley, N. D., and van den Bosch, F. 2011. Derivation and testing of a model to predict selection for fungicide resistance. Plant Pathol. 60:304-313.

26. Hobbelen, P. H. F., Paveley, N. D., Oliver, R. P., and van den Bosch, F. 2013. The usefulness of fungicide mixtures and alternation for delaying the selection of resistance in populations of Mycosphaerella graminicola on winter wheat: A modeling analysis. Phytopathology 103:690-707.

27. Hobbelen, P. H. F., Paveley, N. D., and van den Bosch, F. 2011. Delaying selection for fungicide insensitivity by mixing fungicides at a low and high risk of resistance development: A modelling analysis. Phytopathology 101:1224-1233.

28. Hobbelen, P. H. F., Paveley, N. D., and van den Bosch, F. 2014. The emergence of resistance to fungicides. PlosOne. DOI: 10.1371/journal. pone.0091910

29. Horsten, J. A. H. M. 1979. Acquired resistance to systemic fungicides of Septoria nodorum and Cercosporella herpotrichoides in cereals, Ph.D. thesis. Wageningen University, the Netherlands.

30. Hunter, T., Brent, K. J., and Carter, G. A. 1984. Effects of fungicide regimes on sensitivity and control of barley mildew. Pages 471-476 in: British Crop Protection Conference, Pests and Diseases. British Crop Protection Council, Farnham.

31. Hunter, T., Brent, K. J., Carter, G. A., and Hutcheon, J. A. 1987. Effects of fungicide spray regimes on incidence of dicarboximide resistance in grey mould (Botrytis cinerea) on strawberry plants. Ann. Appl. Biol. 110:515525 .

32. Iwasa, Y., Michor, F., and Nowak, M. A. 2003. Evolutionary dynamics of 
invasion and escape. J. Theor. Biol. 226:205-214.

33. Kalamarakis, A. E., de Waard, M. A., Ziogas, B. N., and Georgopoulos, 1991. Resistance to fenarimol in Nectria haematococca var. cucurbitae. Pest. Biochem. Physiol. 40:212-220.

34. Koenraadt, H., Somerville, C., and Jones, A. L. 1992. Characterization of mutations in the beta-tubuline gene of benomyl-resistant field strains of Venturia inaequalis and other plant pathogenic fungi. Phytopathology 82:1348-1354.

35. Köller, W., and Wilcox, W. F. 1999. Evaluation of tactics for managing resistance of Venturia inaequalis to sterol demethylation inhibitors. Plant Dis. 83:857-863.

36. Kretschmer, M., Leroch, M., Mosbach, A., Walker, A. S., Fillinger, S., Mernke, D., Schoonbeek, H. J., Pradier, J. M., Leroux, P., De Waard, M. A., and Hahn, M. 2009. Fungicide-driven evolution and molecular basis of multidrug resistance in field populations of the grey mould fungus Botrytis cinerea. PLoS Pathog. 5(12).

37. Lalancette, N., Hickey, K. D., and Cole, H., Jr.1987. Effects of mixtures of benomyl and mancozeb on build-up of benomyl-resistant Venturia inaequalis. Phytopathology 77:86-91.

38. LaMondia, J. A. 2001. Management of Euonymus anthracnose and fungicide resistance in Colletotrichum gloeosporioides by alternating or mixing fungicides. J. Environ. Hortic. 19:51-55.

39. Lorenz, G., Saur, R., Schelberger, K., Forster, B., Kung, R., and Zobrist, P. 1992. Long-term monitoring results of wheat powdery mildew sensitivity towards fenpropimorph and strategies to avoid the development of resistance. Vols. 1, 2, and 3; Pages 171-176 in: Brighton Crop Protection Conference: Pests and Diseases. British Crop Protection Council, Farnham.

40. Madden, L. V., Hughes, G., and van den Bosch, F. 2007. The Study of Plant Disease Epidemics. The American Phytopathological Society, St. Paul, MN.

41. Maraite, H., Meunier, S., Gilles, G., and Bal, E. 1985. Evolution de la resistance aux imides cycliques chez Botrytis cinerea sur fraisiers en Belgique. Bull. OEPP 15:387-394.

42. Mavroeidi, V. I., and Shaw, M. W. 2006. Effects of fungicide dose and mixtures on selection for triazole resistance in Mycosphaerella graminicola under field conditions. Plant Pathol. 55:715-725.

43. McCartney, C., Mercer, P. C., Cooke, L. R., and Fraaije, B. A. 2007. Effects of a stobilurin-based spray programme on disease control, green leaf area, yield and development of fungicide-resistance in Mycosphaerella graminicola in Northern Ireland. Crop Prot. 26:1272-1280.

44. McGee, D. C., and Zuck, M. G. 1981. Competition between benomylresistant and sensitive strains of Venturia inaequalis on apple seedlings. Phytopathology 71:529-532.

45. Mernke, D., Dahm, S., Walker, A. S., Lalève, A., Fillinger, S., Leroch, M., and Hahn, M. 2011. Two promoter rearrangements in a drug efflux transporter gene are responsible for the appearance and spread of multidrug resistance phenotype MDR2 in Botrytis cinerea isolates in French and German vineyards. Phytopathology 101:1176-1183.

46. Northhover, J., and Matteoni, J. A. 1986. Resistance of Botrytis cinerea to benomyl and iprodione in vineyards and greenhouses after exposure to fungicides alone or mixed with captan. Plant Dis. 70:398-402.

47. Oxley, S. J. P., Burnett, F., Hunter, T., Fraaije, B. A., Cooke, L. R., Mercer, C., and Gilchrist, A. 2008. Understanding fungicide mixtures to control Rhynchosporium in barley and minimise resistance shifts: HGCA
Project Report No. 436.

48. Samoucha, Y., and Gisi, U. 1987. Use of two- and three-way mixtures to prevent build-up of resistance to phenylamide fungicides in Phytophthora and Plasmopara. Phytopathology 77:1405-1409.

49. Sanders, P. L., Houser, W. L., Parish, P. J., and Cole, H. 1985. Reducedrate fungicide mixtures to delay fungicide resistance and to control selected turfgrass disease. Plant Dis. 69:939-943.

50. Serra, M. C. 2006. On waiting time to escape. J. Appl. Probab. 43:296302.

51. Serra, M. C., and Haccou, P. 2007. Dynamics of escape mutants. Theor. Popul. Biol. 72:167-178

52. Shaw, M. W. 1993. Theoretical-analysis of the effect of interacting activities on the rate of selection for combined resistance to fungicide mixtures. Crop Prot. 12:120-126.

53. Shaw, M. W. 2006. Is there such a thing as a fungicide resistance strategy? A modeller's perspective. Asp. Appl. Biol. 78:37-44.

54. Sierotzki, H., and Scalliet, G. 2013. A review of current knowledge of resistance aspects for the next-generation succinate dehydrgenase inhibitor fungicides. Phytopathology 103:880-887.

55. Taggart, P. J., Cooke, L. R., Mercer, P. C., and Shaw, M. W. 1998. Effects of fungicides used to control Rhynchosporium secalis where benzimidazole resistance is present. Crop Prot. 17:727-734.

56. Tate, K. G., and Samuels, G. J. 1976. Benzimidazole tolerance in Venturia inaequalis in New Zealand. Plant Dis. Rep. 60:706-710.

57. Thygesen, K., Jorgensen, L. N., Jensen, K. S., and Munk, L. 2009. Spatial and temporal impact of fungicide spray strategies on fungicide sensitivity of Mycosphaerella graminicola in winter wheat. Eur. J. Plant Pathol. 123:435-447.

58. Turechek, W. W., and Köller, W. 2004. Managing resistance of Venturia inaequalis to the strobilurin fungicides. Plant Health Progress doi:10.1094/PHP-2004-0908-01RS

59. Vali, R. J., and Moorman, G. W. 1992. Influence of selected fungicide regimes on frequency of dicarboximide-resistant and dicarboximidesensitive strains of Botrytis cinerea. Plant Dis. 76:919-924.

60. van den Berg, F., van den Bosch, F., and Paveley, N. D. 2013. Optimal fungicide application timings for disease control are also an effective antiresistance strategy: A case study for Zymoseptoria tritici (Mycosphaerella graminicola) on wheat. Phytopathology 103:1209-1219.

61. van den Bosch, F., and Gilligan, C. A. 2008. Models of fungicide resistance. Annu. Rev. Phytopathol. 46:123-147.

62. van den Bosch, F., McRoberts, N., van den Berg, F., and Madden, L. 2008. The basic reproduction number of plant pathogens: Matrix approaches to complex dynamics. Phytopathology 98:239-249.

63. van den Bosch, F., Oliver, R., van den Berg, F., and Paveley, N. D. 2014. Governing principles can guide fungicide resistance management tactic. Annu. Rev. Phytopathol. 52:175-195.

64. van den Bosch, F., Paveley, N. D., Shaw, M. W., Hobbelen, P., and Oliver, R. 2011. The dose rate debate: Does the risk of fungicide resistance increase or decrease with dose? Plant Pathol. 60:597-606.

65. Zhang, C.-Q., Zhang, Y., and Zhu, G. N. 2008. The mixture of kresoximmethyl and boscalis, an excellent alternative controlling grey mold caused by Botrytis cinerea. Ann. Appl. Biol. 153:205-213.

66. Zhu, S. S., Liu, X. L., Wang, Y., Wu, X. H., Liu, P. F., Li, J. Q., Yuan, S. K., and Si, N. G. 2007. Resistance of Pseudoperonospora cubensis to flumorph on cucumber in plastic houses. Plant Pathol. 56:967-975. 